\title{
Gamma Radiation Synthesis of Silver Nanoparticles/Chitosan Composites with Antimicrobial Properties
}

\author{
EDUARD-MARIUS LUNGULESCU1 ${ }^{1}$, RADU SETNESCU ${ }^{1,2}$, NICOLETA-OANA NICULA ${ }^{\text {* }}$, \\ IOANA ION ${ }^{1}$, VIRGIL MARINESCU ${ }^{1}$ \\ ${ }^{1}$ National Institute for Research and Development in Electrical Engineering ICPE-CA, 313, Splaiul Unirii, 030138, \\ Bucharest, Romania \\ ${ }^{2}$ Valahia University of Targoviște, 13 Sinaia Alley, 130004, Targoviste, Romania
}

\begin{abstract}
Composites of Silver nanoparticles/chitosan were obtained in aqueous solution, in-one step and eco-friendly synthesis, under ambiental conditions, using gamma irradiation. The radiochemical synthesis enabled obtaining of controlled size, monodisperse and high stability Silver nanoparticles. The obtained composites presented UV-Vis surface plasmon resonance comprised between 406-414 nm, depending on composition of the reactant system, spherical shape and narrow particle size distributions, with mean dimensions between 3-55 $\mathrm{nm}$, and good antibacterial properties proven against Staphylococcus aureus and Escherichia coli. The influence of the Silver ions/chitosan ratio and of the $\mathrm{pH}$ of the initial solution on the final Ag Np properties is also discussed.
\end{abstract}

Keywords: Chitosan, Silver nanoparticles, antimicrobial composites, gamma irradiation

\section{Introduction}

Due to their peculiar properties related to their high specific area, colloidal systems of Silver nanoparticles ( $\mathrm{Ag} \mathrm{Np}$ ) have a wide range of applications, such as catalysts, sensors and biosensors, pharmaceuticals (e.g. diagnostics, drug delivery or tumoral therapies), electric and electronic devices a.s.o. The special microbicidal properties of Silver nanoparticles are exploited in household and health care products, such as medical (e.g. prosthetics and orthotics) and cosmetic equipment coatings, in the food industries (e.g. packaging materials) a.s.o. [1-3].

Recent studies shown that Ag Np are highly efficient against different microbial agents such as fungi, bacteria, viruses [4-6], opening new ways for development of new Ag Np based materials for biomedical applications, of great importance in the current global pandemic context caused by the spread of SarsCoV-2.

Ag Np can be synthesized by different ways such as: chemical [7, 8], physical [9] and biological [8, 10, 11]. Generally, the chemical, conventional, methods are performed in aqueous solutions of Silver salt precursor (i.e. $\mathrm{AgNO}_{3}$ ) in the presence of some stabilizing and reducing toxic agents (e.g. hydrazine, sodium borohydride, etc.).

In contrast with the conventional methods, the radiochemical synthesis takes place in one-step and under mild conditions of temperature and pressure, leading to well dispersed systems with narrow particle size distribution-and does not involve the use of chemical toxic reduction agents nor waste release, being considered an eco-friendly method of synthesis. The dimensional control of nanoparticles can be achieved by varying a small number of synthesis parameters, especially by controlling the irradiation dose $[12,13]$.

The mechanism of radiochemical synthesis is based on the reduction of Silver ions in the presence of strong reducing species, especially hydrated electrons $\left(\mathrm{e}_{\mathrm{aq}}{ }^{-}\right)$and hydrogen radicals $(\mathrm{H} \cdot)$, induced by water radiolysis [14]:

$$
\begin{aligned}
& \mathrm{H}_{2} \mathrm{O} \stackrel{\gamma}{\longrightarrow} \mathrm{e}_{\mathrm{aq}}{ }^{-}, \mathrm{H}_{3} \mathrm{O}^{+}, \mathrm{H}^{\bullet}, \mathrm{OH}^{\bullet}, \mathrm{H}_{2}, \mathrm{H}_{2} \mathrm{O}_{2}, \mathrm{HO}_{2}{ }^{\bullet} \\
& \mathrm{Ag}^{+}+\mathrm{e}_{\mathrm{aq}}{ }^{-} \longrightarrow \mathrm{Ag}^{0} \\
& \mathrm{Ag}^{+}+\mathrm{H} \cdot \longrightarrow \mathrm{Ag}^{0}+\mathrm{H}^{+}
\end{aligned}
$$

*email: nicoleta.nicula@icpe-ca.ro 
On the other side, the hydroxyl radicals $(\mathrm{OH} \cdot)$ present an oxidant character and can oxidize Silver ions or atoms to higher oxidation states [15]. To prevent this effect, scavengers such as secondary or tertiary alcohols should be used [11-13, 16].

Hence, the need to use chemical reducing agents, as well as their associated side effects, is avoided. Moreover, by varying the irradiation dose, the number of zero-valent nuclei can be controlled. The formed metal atoms are evenly distributed throughout the solution due to the action of ionizing radiation which can randomly reduce the metal ion. These newly formed metal atoms act as individual nucleation centres and coagulate into dimers [17].

Nanoparticle agglomeration of radiochemically synthesized nanoparticles is avoided by different socalled stabilizing agents, such as polyvinyl alcohol (PVA) [13, 16, 18], polyvinylpyrrolidone (PVP) [11], gelatine [19], chitosan [20, 21], a.s.o. These polymers can create fine coatings onto the particles resulting in a repulsive sterical force which keeps the nanoparticles away from each other - sterical stabilization [22, 23].

In previous studies it was found that radiochemically synthesized Silver nanoparticles capped both with polyvinyl alcohol (PVA) and polyvinylpyrrolidone (PVP), respectively, presented strong bactericide effects [13] as well as mitoinhibitory effect [11], suggesting their potential application as antitumoral agents.

In this paper, $\mathrm{Ag} \mathrm{Np/chitosan} \mathrm{composites} \mathrm{were} \mathrm{synthesized} \mathrm{by} \mathrm{gamma} \mathrm{radiation,} \mathrm{in} \mathrm{aqueous} \mathrm{solution}$ in the presence of Silver ions salt precursor and chitosan which was used both as capping agent and free hydroxyl radical scavenger.

Chitosan, one of the most naturally abundant polysaccharides, obtained by chitin deacetylation [24], is a biodegradable, biocompatible and non-toxic polymer. Hence, it is very attractive for use in various fields, especially for biomedical applications, as for example: drug carrier, wound accelerator, haemostatic agent, fat binder, etc. [25]. The influences of the concentration ratio of chitosan and Silver ions and of the solution $p \mathrm{H}$ on the final properties of $\mathrm{Ag} \mathrm{Np}$ were studied. Also, the antibacterial activity against Staphylococcus aureus and Escherichia coli was investigated in this paper.

\section{Materials and methods}

\subsection{Materials}

The Silver Nitrate (Mw=169,87, p.a., Chemical Company Iași, RO) was used as a salt precursor of Silver ions. Medium molecular weight chitosan with deacetylation $76 \%$ and viscosity 402 CPS (Sigma Aldrich) was used as polymer matrix and capping agent. Glacial acetic acid (min. 99.5\%, Chemical Company Iași, RO) was used to assist the chitosan dissolution in deionized water. All used materials were of analytical grade.

\subsection{Obtaining of Silver nanoparticles/chitosan composites}

Solutions with different ratios of $\mathrm{Ag} \mathrm{Np} /$ chitosan and different $p \mathrm{H}$ values were prepared and irradiated as shown in Table 1.

The chitosan was dissolved in $2 \%$ aqueous solution of acetic acid (v/v), prepared with deionized water, at room temperature under magnetic stirring for about $4 \mathrm{~h}$. Then, the solution was kept overnight in order to achieve the complete chitosan dissolution. The respective quantity of Silver nitrate (Table 1) was added steadily to the chitosan solution, at room temperature, under magnetic stirring for about $2 \mathrm{~h}$. The $p \mathrm{H}$ of the obtained solution was about 3.8. Each chitosan $/ \mathrm{Ag}^{+}$solution was divided into two parts: for one part, the $p \mathrm{H}$ was raised at 6.8 by pouring a solution of $\mathrm{NaOH}(3 \mathrm{~N})$ under continuous stirring; the second one was kept as resulted from the above described preparation. Both solution series were purged with Argon gas for about $30 \mathrm{~min}$ in order to remove the dissolved oxygen.

Then, the solutions, hermetically enclosed in plastic bottles and wrapped in aluminium foil, were $\gamma$ irradiated in a laboratory facility equipped with ${ }^{60} \mathrm{Co}$ isotope (Ob-Servo Sanguis, HU), at room temperature, at a dose of $20 \mathrm{kGy}$ (Dose rate: $0.7 \mathrm{kGy} / \mathrm{h}$ ). 
Table 1 - Prepared solutions of chitosan/AgNp

\begin{tabular}{|c|c|c|c|}
\hline Sample code & $\begin{array}{c}\text { Chitosan } \\
(\boldsymbol{\%})\end{array}$ & $\begin{array}{c}\text { Silver nitrate } \\
(\mathbf{m M})\end{array}$ & \multirow{2}{*}{$\mathbf{p H}$} \\
\hline S1 & 1.0 & 1.0 & \multirow{2}{*}{3.8} \\
\hline S2 & 1.0 & 5.0 & \\
\hline S3 & 0.5 & 1.0 & \multirow{2}{*}{6.8} \\
\hline S 5 & 0.5 & 5.0 & \\
\hline S6 & 1.0 & 1.0 & \\
\hline S7 & 1.0 & 5.0 & \\
\hline S8 & 0.5 & 1.0 & \\
\hline
\end{tabular}

\subsection{Characterization of chitosan/Silver nanoparticles composites}

$U V$-Vis spectroscopy (Jasco V-570, JP) was performed in the spectral range of 300-700 $\mathrm{nm}$ on deionized water diluted samples. The dilution factors were 10 for the solutions with the concentration of $1 \mathrm{mM} \mathrm{Ag}^{+}$(Table 1) and 100 for $5 \mathrm{mM} \mathrm{Ag}^{+}$. An irradiated solution of chitosan free of Silver ions was used as reference.

The Scanning Electron Microscopy images were recorded on uncoated samples with an FE-SEM model Auriga, Carl Zeiss, Germany, with an accelerating voltage of $5 \mathrm{kV}$.

The hydrodynamic diameter and particles size distribution were measured on diluted aqueous solutions by Dynamic Light Scattering (DLS) technique, using a 90 Plus nanoparticle size analyser (Brookhaven Instruments Corporation) equipped with $35 \mathrm{~mW}$ solid-state laser with $660 \mathrm{~nm}$ wavelength. DLS measurements were performed at a scattering angle of $90^{\circ}$ and a temperature of $25^{\circ} \mathrm{C}$.

The antibacterial susceptibility of irradiated solutions was assessed both qualitatively and quantitatively, against Gram-negative strain Escherichia coli ATCC 25922 and Gram-positive strain Staphylococcus aureus ATCC 9737.

From each tested strain, a bacterial suspension with a cell density of 0.5 McFarland $\left(1.5 \times 10^{8}\right.$ $\mathrm{CFU} / \mathrm{mL}$ ) was prepared in sterile distilled water. The bacterial suspensions were seeded on solid Muller Hinton (MH) medium, and $10 \mu \mathrm{L}$ of each test sample was inoculated into previously seeded plates. The inoculated plates were left at room temperature for $5 \mathrm{~min}$ and then incubated at $37^{\circ} \mathrm{C}$ for $24 \mathrm{~h}$.

The qualitative evaluation was performed using an adapted version of the Kirby Bauer agar diskdiffusion method and the interpretation of the results was done according to the CLSI standard [26]. The quantitative evaluation involving the serial dilution of the irradiated solution, up to $1 / 32$, was made in order to obtain the minimal inhibitory concentration (MIC).

\section{Results and discussions}

\section{UV-Vis spectroscopy}

A first, qualitative, indication of the successful synthesis of Silver nanoparticles was given by the color changing of irradiated chitosan solution, the solution becoming darker as the concentration of the Silver atoms increases (Figure 1).

The UV-Vis spectra (Figure 2) recorded on the irradiated Ag Np/chitosan composites confirmed the formation of $\mathrm{Ag} \mathrm{Np}$, exposing a well-defined and symmetric SPR (Surface Plasmon Resonance) maximum, characteristic to Silver nanoparticles [27]. According to [28] the position, height and FWHM (Full Width at Half Maximum) of the SPR provide qualitative information related to the size, concentration and dispersion degree of Silver nanoparticles. The main characteristics of the SPR of the synthesized Ag Np/chitosan composites are presented in Table 2. Correlation of the UV information inferred by Table 2 with the experimental parameters from Table 1 gives an overview of the influence of synthesis parameters on the final characteristics of radiochemically synthesized Silver nanoparticles. 


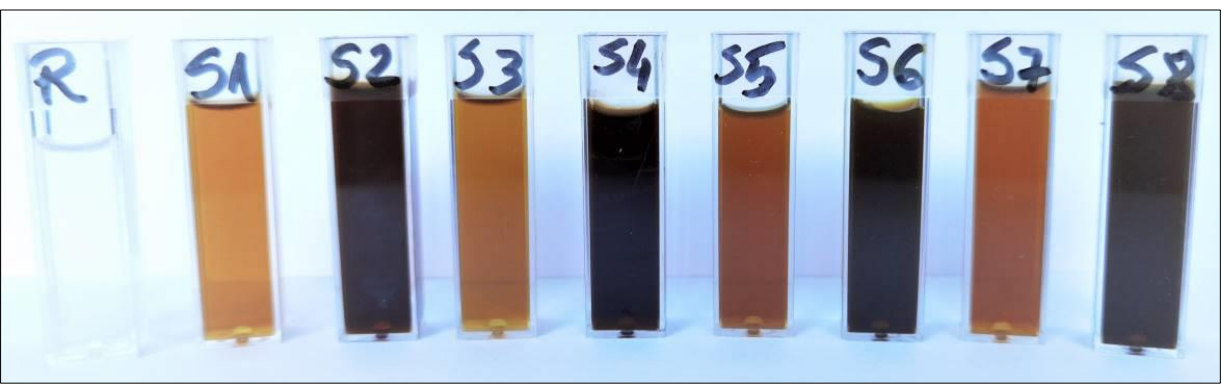

Figure 1. The colour change of irradiated $\mathrm{Ag} \mathrm{Np} /$ chitosan composites (Table 1 for the sample codes; $\mathrm{R}=$ reference, free of Silver ions chitosan solution)

Table 2. SPR characteristics of irradiated Ag Np/chitosan composites

\begin{tabular}{|c|c|c|c|}
\hline Sample code & $\begin{array}{c}\lambda_{\text {SPR }} \\
(\mathbf{n m})\end{array}$ & $\begin{array}{c}\text { Absorbance* } \\
(\mathbf{a . u .})\end{array}$ & $\begin{array}{c}\text { FWHM } \\
(\mathbf{n m})\end{array}$ \\
\hline S1 & 412 & 13.3 & 75.7 \\
\hline S2 & 414 & 54.2 & 100.9 \\
\hline S3 & 410 & 14.0 & 77.5 \\
\hline S5 & 412 & 66.0 & 111.9 \\
\hline S6 & 412 & 17.7 & 66.5 \\
\hline S7 & 414 & 58.3 & 95.6 \\
\hline S8 & 406 & 15.7 & 76.4 \\
\hline
\end{tabular}

* the values were obtained by multiplying the recorded absorbance with the dilution factor

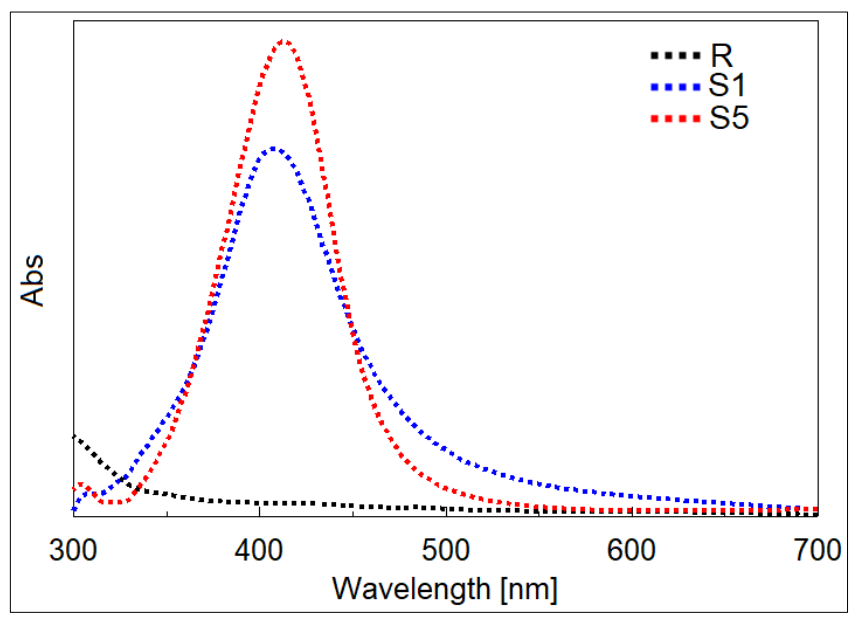

Figure 2. Typical UV-Vis absorption spectra recorded on the irradiated Ag Np/chitosan composites

Generally, a hypsochromic shift of the SPR position of about $2 \mathrm{~nm}(p \mathrm{H}=3.8)$ and of about 6-8 nm $(p \mathrm{H}=6.8)$ is observed with the decrease of chitosan concentration. This indicates that the average size of the Silver nanoparticles decreases with the concentration of chitosan $[12,13]$. Lower concentration of chitosan seems to be more beneficial for obtaining of smaller size nanoparticles with a high conversion yield of Silver ions.

The influence of the $p \mathrm{H}$ solution is observed from both the absorbance and FWHM values. The absorbance increase with the $p \mathrm{H}$ values suggests that the radiochemical conversion of Silver ions is higher at higher $p \mathrm{H}$ values, increasing so the concentration of Ag Np. The FWHM values are higher at $p \mathrm{H}=3.8$, suggesting a higher size dispersion of Silver nanoparticles. All these aspects could be explained by the fact that in acidic medium, the chitosan chain might be broken, reducing its stabilizing capacity of nanoparticles [29]. Therefore, the size of Silver nanoparticles agglomerates become larger resulting in a broader nanoparticles dispersion. 


\section{Dynamic Light Scattering (DLS)}

DLS analysis confirmed the results of UV-Vis spectroscopy: the mean diameter of nanoparticles is smaller at higher $p \mathrm{H}$ values. In Table 3, the mean hydrodynamic diameter of the nanoparticles, as well as the size distribution of the nanoparticles calculated from DLS are expressed as a distribution by number, using the cumulative analysis of a multimodal size distribution model (MSD).

Table 3. The values of the mean diameter of radiation-synthesized $\mathrm{Ag} \mathrm{Np}$

\begin{tabular}{|c|c|}
\hline Sample code & $\begin{array}{c}\text { Mean diameter } \\
\text { (nm) }\end{array}$ \\
\hline S1 & $25.3 \pm 0.017$ \\
\hline S2 & $55.5 \pm 0.030$ \\
\hline S3 & $10.4 \pm 0.015$ \\
\hline S5 & $24.7 \pm 0.025$ \\
\hline S6 & $8.5 \pm 0.015$ \\
\hline S7 & $4.6 \pm 0.012$ \\
\hline S8 & $3.2 \pm 0.014$ \\
\hline
\end{tabular}

\section{Scanning Electronic Microscopy (SEM)}

The SEM analysis was used to obtain information about the shape of the synthesized Silver nanoparticles. The SEM micrography shown that obtained nanoparticles have uniform morphology, spherical shape and a homogeneous distribution of particles in the structure of the polymer matrix (Figure 3). However, it should be noted that it was very difficult to obtain clear SEM images, especially at high magnifications, due to both the small sizes of the synthesized Ag nanoparticles and charging effect of the sample, respectively.

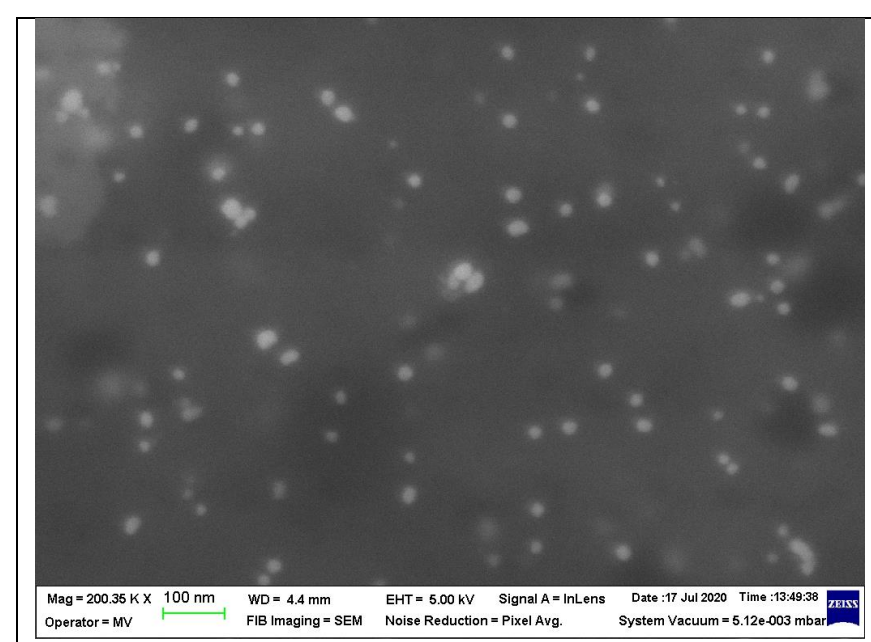

a)

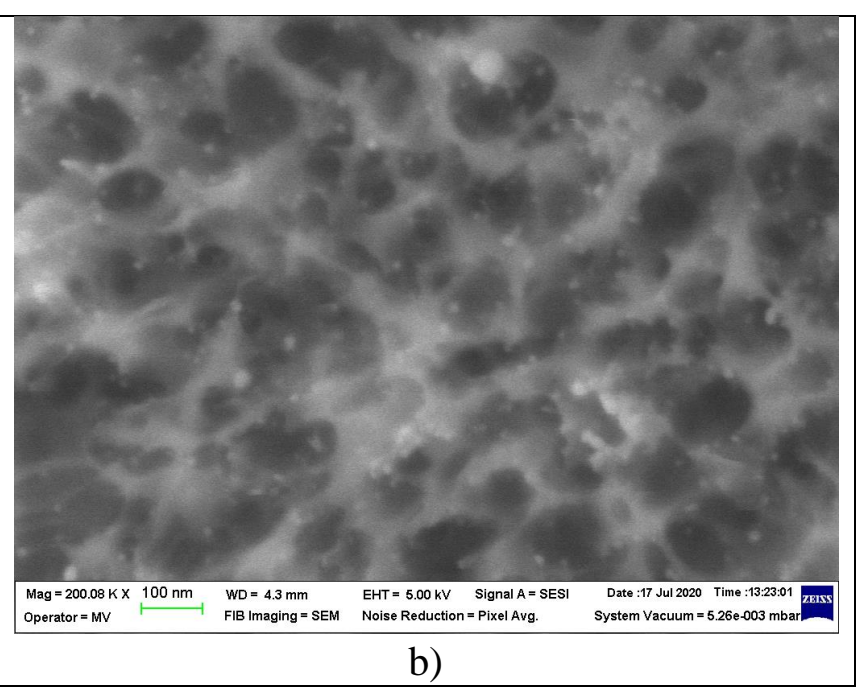

b)

Figure 3. SEM micrography of: S1 (a) and S5 (b) samples

\section{Antimicrobial susceptibility}

The antimicrobial susceptibility of the irradiated solutions was evaluated against Staphylococcus aureus and Escherichia coli, two bacteria frequently used as models for Gram-positive and, respectively Gram-negative strains [28]. All chitosan/AgNp solutions exhibited antimicrobial efficiency, characterized by inhibition of the development of used strains on the treated area, with or without clear inhibition zones (Figure 4, Table 4).

It's worth to be noted, that the chitosan free of Silver nanoparticles shown lower antimicrobial efficiency, its surface being partially attacked by the tested strains (e.g. development on the sample surface of a small number of bacterial colonies, their number being higher for $S$ aureus strain). 


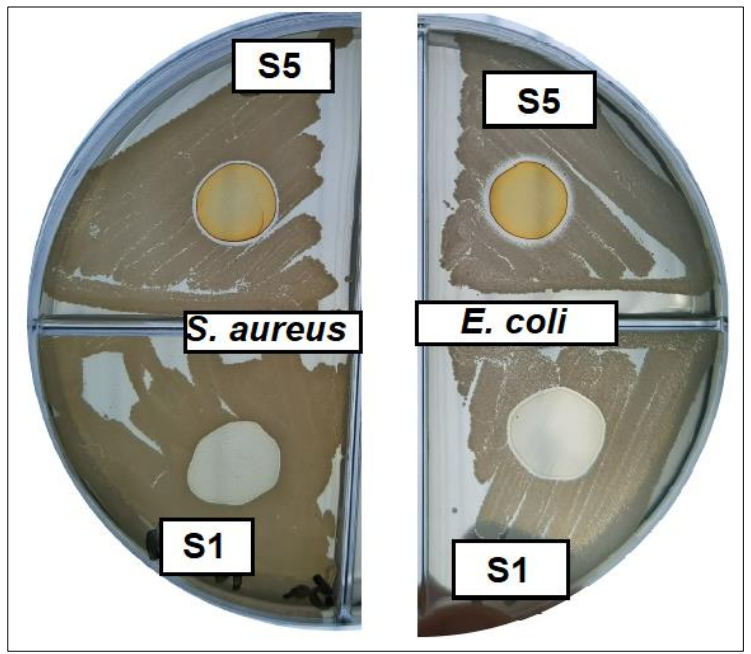

Figure 4. The antimicrobial efficiency against $S$. aureus and $E$. coli

As can be observed, the antimicrobial activity seems to be higher for E. coli than S. aureus (Table 4). All tested samples against $E$. coli presented antibacterial activity with clear inhibition zone (bactericidal effect), while, for S. aureus, this effect was evident only for the samples S5 (Figure 4), S7 and S8, respectively.

The $p \mathrm{H}$ of the solution is important in the inhibition growth of bacteria. It can be observed that higher values of $p \mathrm{H}$ lead to higher antimicrobial efficiency on both tested strains. It was found that an acidic $\mathrm{pH}$ of the solution could diminish or prevent the apparition of a clear inhibition zone [26]. Similar effects were observed in our case for samples S1-S4, especially for the S. aureus strain.

The mean size of the Silver nanoparticle could influence the antibacterial efficiency of the composite: the smaller the nanoparticles, the higher the antibacterial efficiency $[11,13,16]$

Table 4. Qualitative and quantitative assessment of the antimicrobial properties

\begin{tabular}{|c|c|c|c|c|}
\hline \multirow{2}{*}{ Sample code } & \multicolumn{2}{|c|}{ Antimicrobial activity } & \multicolumn{2}{c|}{ Dilutions values for MIC determination } \\
\cline { 2 - 5 } & S. aureus & $\boldsymbol{E}$. coli & S. aureus & E. coli \\
\hline R & - & - & untested & untested \\
\hline S1 & $+/-$ & + & $1 / 16^{*}$ & $1 / 16$ \\
\hline S2 & $+/-$ & + & $1 / 4^{*}$ & $1 / 8^{*}$ \\
\hline S3 & $+/-$ & + & $1 / 8^{*}$ & $1 / 8^{*}$ \\
\hline S5 & $+/-$ & + & $1 / 16^{*}$ & $1 / 8^{*}$ \\
\hline S6 & + & + & $1 / 16^{*}$ & $1 / 32$ \\
\hline S7 & $+/-$ & + & $1 / 16$ & $1 / 32$ \\
\hline S8 & + & + & $1 / 32^{*}$ & $1 / 32^{*}$ \\
\hline "_w no & + & + & 1.32 \\
\hline
\end{tabular}

“_" no antimicrobial efficiency; "+” antimicrobial efficiency with inhibition zone; "+/_" antimicrobial efficiency without inhibition zone; * antimicrobial efficiency without inhibition zone

The MIC of tested solution was ranged from $1 / 4$ for S2 (S. aureus) up to $1 / 32$ for S8 (S. aureus and E. coli) is a proof for the high antibacterial efficiency of obtained $\mathrm{Ag} \mathrm{Np} /$ chitosan composites.

Even the antimicrobial activity of $\mathrm{Ag} \mathrm{Np}$ is not fully elucidated, few action mechanisms are universally accepted: release of Silver ions, drilling of bacterial membranes, interaction with disulphide and sulfhydryl groups of enzymes, leading to disruption of metabolic processes and DNA alteration [30].

The bactericide effect of $\mathrm{Ag} \mathrm{Np/chitosan} \mathrm{is} \mathrm{due} \mathrm{to} \mathrm{the} \mathrm{structural} \mathrm{compatibility} \mathrm{between} \mathrm{chitosan} \mathrm{and}$ Gram-negative bacteria (such as E. coli): the polycationic structure of chitosan is favourable to electrostatic interactions with the lipopolysaccharides and cell surface proteins (anionic structures) of Gram-negative bacteria [31]. Also, the smaller Ag Np (S7 and S8) possesses superior antimicrobial activity against Gram-negative bacteria (E. coli), due to both the thin peptidoglycan layer and the outer porous lipid membrane which enables more easy penetration of nanoparticles into the intracellular space [11]. 


\section{Conclusions}

The Silver nanoparticles/chitosan composites were obtained by gamma irradiation in aqueous solution, in one-step synthesis without the use of chemical reducing agents.

The synthesized composites exhibit SPR absorption peaks between 406-414 nm, spherical shape of Ag nanoparticles and a narrow size distribution with mean diameter between 3-55 nm.

The composites presented good antibacterial activity against both Gram-positive (S. aureus) and Gram-negative bacteria (E. coli). The $p \mathrm{H}$ of the solution, as well as the size of the $\mathrm{Ag} \mathrm{Np}$ played an important role on the antibacterial efficiency.

Acknowledgements: The financial support was provided by Ministry of Research and Innovation, through PN 19310101-46N/2019, contract 30PFE/2018 (between National R\&D Institute for Electrical Engineering ICPE-CA and Romanian Ministry of Research and Innovation - MCI), contract 3PS/28.08.2019 and contract 22SOL/2020

\section{References}

1.CHOUHAN, N., Silver Nanoparticles: Synthesis, Characterization and Applications, Silver Nanoparticles - Fabrication, Characterization and Applications, Khan Maaz, IntechOpen, 2018. DOI: 10.5772/intechopen.75611.

2. GURUNATHAN, S., PARK, J.H., HAN, J.W., KIM, J.H., Comparative assessment of the apoptotic potential of Silver nanoparticles synthesized by Bacillus tequilensis and Calocybe indica in MDA-MB231 human breast cancer cells: Targeting p53 for anticancer therapy, Int. J. Nanomed., 10, 2015, 42034222.

3. CHERNOUSOVA, S., EPPLE, M., Silver as antibacterial agent: Ion, nanoparticle, and metal, Angew. Chem. Int. Ed., 52, 2013, 1636-1653.

4.GALDIERO, S., FALANGA, A., VITIELLO, M., CANTISANI, V.M., GALDIERO, M., Silver nanoparticles as potential antiviral agents, Molecules, 16, 2011, 8894-8918.

5.KHANDELWAL, N., KAUR, G., KUMAR, N., TIWARI, A., Application of Silver nanoparticles in viral inhibition: a new hope for antivirals, Dig. J. Nanomater. Bios., 9(1), 2014, 175-186.

6. KERRY, R.G., MALIK, S., REDDA, Y.T., SAHOO, S., PATRA, J.K., MAJHI, S., Nano-based approach to combat emerging viral (NIPAH virus) infection, Nanomed. Nanotechnol. Biol. Med., 18, 2019, 196-220.

7. GUZMAN, M.G., DILLE, J., GODET, S., Synthesis of Silver nanoparticles by chemical reduction method and their antibacterial activity, Int. J. Chem. Biomol. Eng., 2(3), 2009, 104-111.

8. GUDIKANDULA, K., MARINGANTI, S.C., Synthesis of Silver nanoparticles by chemical and biological methods and their antimicrobial properties, J. Exp. Nanosci., 11(9), 2016, 714-721.

9. MUSTATEA, G., CALINESCU, I., DIACON, A., BALAN, L. Photoinduced Synthesis of Silver/ polymer Nanocomposites, Mater. Plast., 51(1), 2014, 17-21.

10. PROKS, M., BORCAN, F., CHEVERESAN, A., PANZARU I., GUTA, B.A., CORICOVAC, D., PAUNESCU, V., LAZUREANU, V., Study on the Release and Bioevaluations of Green Silver Nanoparticles Entrapped Inside Polymer-based Nanovesicles, Mater. Plast., 55(4), 2018, 696-699.

11. FIERASCU, R.C., FIERASCU, I., LUNGULESCU E.M., NICULA, N., SOMOGHI R., DITU, L.M., UNGUREANU, C., SUTAN, A.N., DRAGHICEANU, O.A., PAUNESCU, A., SOARE, L.C., Phytosinthesis and radiation-assisted methods for obtaining metal nanoparticles, J. Mater. Sci., 55, 2020, 1915-1932.

12. ABEDINI, A., DAUD, A.R., HAMID, M.A.A., OTHMAN, N.K., SAION, E., A review on radiationiduced nucleation and growth of colloidal metallic nanoparticles, Nanoscale Res. Lett., 8, 2013, 474484.

13. LUNGULESCU, E.M., SBARCEA, G., SETNESCU R., NICULA, N., DUCU, R., LUPU, A.M., ION, I., MARINESCU V., Gamma Radiation Synthesis of Colloidal Silver Nanoparticles, Rev. Chim., 70(8), 2019, 2826-2830. 
14. BELLONI, J., Nucleation, growth and properties of nanoclusters studied by radiation chemistry. Application to catalysis, Catal. Today, 113, 2006, 141-156.

15. ROJAS. J., CASTANO, C., Production of palladium nanoparticles supported on multiwalled carbon nanotubes by gamma irradiation, Radiat. Phys. Chem. 81, 2012, 16-21.

16. EGHBALIFAM, N., FROUNCHI, M., DADBIN, S., Antibacterial Silver nanoparticles in polyvinyl alcohol/sodium alginate blend produced by gamma irradiation, Int. J. Biol. Macromol., 80, 2015, 170176.

17. RAO, Y., BANERJEE, D., DATTA, A., DAS, S., GUIN, R., SAHA, A., Gamma irradiation route to synthesis of highly re-dispersible natural polymer capped Silver nanoparticles, Radiat. Phys. Chem. 79, 2010, 1240-1246.

18. WIGUNA, P.A., DJUHANA, D., IMAWAN, C., UMAR, A. Physicochemical properties of colloidal Ag/PVA nanoparticles synthesized by gamma irradiation, J. Phys.: Conf. Ser. 1428, 2020, 012022

19. SOLIMAN, Y.S., Gamma-radiation induced synthesis of Silver nanoparticles in gelatin and its application for radiotherapy dose measurements, Rad. Phys. Chem., 102, 2014, 60-67.

20. CHEN, P., SONG, L., LIU, S., FANG, Y., Synthesis of Silver nanoparticles by $\gamma$-ray irradiation in acetic water solution containing chitosan, Rad. Phys. Chem., 76(7), 2007, 1165-1168.

21. HETTIARACHCHI, M.A., WICKRAMARACHCHI, P.A.S.R., Synthesis of chitosan stabilized Silver nanoparticles using gamma ray irradiation and characterization, J. Sci. Univ. Kelaniya, 6, 2011, 65-75.

22. KULKARNI, P., SURESHKUMAR, R., BISWASA, P., Multiscale simulation of irreversible deposition in presence of double layer interactions. J. Colloid Interface Sci. 260, 2003, 36 - 48.

23. OTT, L.S., FINKE, R.G., Transition-metal nanocluster stabilization for catalysis: a critical review of ranking methods and putative stabilizers. Coord. Chem. Rev. 251, 2007, $1075-1100$.

24. KUMAR, M.N.V.R., MUZZARELLI, R.A.A.A., MUZARELLI, C., SASHIWA, H., DOMB, A.J., Chitosan Chemistry and Pharmaceutical Perspectives, Chem. Rev., 104, 2004, 6017-6084.

25. RAMYA, R., VENKATESAN, J., KIM, S.K., SUDHA, P.N., Biomedical Applications of Chitosan: An Overview, J. Biomater. Tissue Eng., 2, 2012, 100-111.

26. CLINICAL LABORATORY STANDARDS INSTITUTE, Performance standards for antimicrobial susceptibility testing, M100-S29, ed. 29, 2019.

27. SILIMAN, Y.S., Gamma-radiation induced syhthesis of Silver nanoparticles in gelatin and its application for radiotherapy dose measurements, Radiat. Phys. Chem., 102, 2014, 60-67.

28. AGNIHOTRI, S., MUKHERJI, S., MUKHERJI, S., Size-controlled Silver nanoparticles synthesized over the range 5-100 $\mathrm{nm}$ using the same protocol and their antibacterial efficacy, $R S C A d v$., 4, 2014, 3974-3983.

29. SUN, C., QU, R., CHEN, H., JI, C., WANG, C., SUN, Y., WANG, B., Degradation behavior of chitosan chains in the "green" synthesis of gold nanoparticles, Carbohydr. Res., 343(15), 2008, 25952599.

30. IAVICOLI, I., FONTANA, L., LESO, V., BERGAMASCHI A., The Effects of Nanomaterials as Endocrine Disruptors, Int. J. Mol. Sci., 14, 2013, 16732-16801.

31. KONG, M., CHEN, X.G., XING, K., PARK, H.J., Antimicrobial properties of chitosan and mode of action: a state of the art review, Int. J. Food Microbiol., 144, 2010, 51-63.

Manuscript received: 28.09 .2020 